\title{
SOCAR Proceedings
}

\author{
Reservoir and Petroleum Engineering
}

SOCAR

journal home page: http://proceedings.socar.az

\section{МИКРОСТРУКТУРНАЯ СМАЧИВАЕМОСТЬ НЕФТЕГАЗОКОНДЕНСАТНЫХ ЗОН КАРАЧАГАНАКСКОГО МЕСТОРОЖДЕНИЯ}

\author{
Н.Н. Михайлов ${ }^{1,2}$, Л.С.Сечина ${ }^{* 2}$ \\ ${ }^{1}$ Российский государственный университет нефти и газа (НИУ) им. И.М. Губкина, Москва, Россия;; \\ ${ }^{2}$ Институт проблем нефти и газа Российской академии наук, Москва, Россия
}

\author{
Microstructural Wettability of Oil and Gas Condensate Zones of \\ the Karachaganak Field \\ N.N. Mikhailov ${ }^{1,2}$, L.S. Sechina ${ }^{2}$ \\ ${ }^{1}$ Gubkin Russian State University of Oil and Gas (National Research University), Moscow, Russia; \\ ${ }^{2}$ Oil and Gas Research Institute of the Russian Academy of Sciences, Moscow, Russia
}

\begin{abstract}
A b stract
The Karachaganak field is represented by gas condensate and oil zones, a convenient object for studying changes in microstructural wettability during the transition from one zone to another. Microstructural wettability was characterized by a hydrophobization coefficient, $\Theta_{\mathrm{H}}$, which determines the proportion of the pore surface area occupied by adsorbed hydrocarbons. It was found that $\Theta_{\text {н }}$ of the samples of the gas and gas condensate zones is the same (on average 0.140 ), the oil zone - on average 0.250. Analysis of the IR spectra of extracted hydrocarbons showed that the microstructural wettability of the oil zone contains more aromatic, aliphatic, oxidized and sulfur-containing structures and fewer branched structures than in the gas condensate zone. The microstructural wettability of carbonate reservoirs depends on the hydrocarbon composition of the adsorbed oil.
\end{abstract}

\author{
Keywords: \\ Microstructural wettability; \\ Hydrophobic coefficient; \\ Hydrocarbons; \\ Spectral coefficients.
}

(c) 2021 «OilGasScientificResearchProject» Institute. All rights reserved.

Смачиваемость играет ключевую роль в любом процессе извлечения нефти и газа, а также влияет на выпадение и подвижность конденсата в процессе разработки залежи. Пренебрежение эффектами смачивания обуславливает ошибочные распределения насыщенности при геологическом моделировании, а также некачественные прогнозные показатели разработки при гидродинамическом моделировании. Целый ряд нефтяных месторождений с гидрофобной характеристикой коллектора невозможно эффективно разрабатывать с помощью традиционного заводнения, а запасы нефти в таких коляекторах являются трудно извлекаемыми.

Смачиваемость является серьезной проблемой в задачах многофазной фильтрации нефти, начиная с миграции нефти от материнских пород и заканчивая усовершенствованными процессами добычи, такими как нагнетание щелочей или попеременное введение $\mathrm{CO}_{2}$ и воды. На протя-

*E-mail: folko200@mail.ru

http://dx.doi.org/10.5510/OGP2021SI200551 жении длитедьного периода во многих научноисследовательских работах уделялось внимание эффекту смачиваемости при добыче нагнетанием воды. Большая часть знаний о коллекторах основана на предположении, что большинство коллекторов хорошо впитывают воду, т.е. в пласте порода сохраняет способность впитывать воду при наличии в ней нефти и, что вода изначально присутствует в пластовой ловушке и сохраняется в порах при помощи капиллярных сил и в виде плёнок на поверхности пор, занятых нефтью, в то время как последняя накапливается в колдекторе. Также это наблюдается в хранилищах керна, но часто приписывается дефектам и погрешностям, связанным с добычей и исследованием керна. Большинство экспериментов проводятся с очищенным от нефти и газа керном, так как это даёт результаты, эквивалентные тем, которые получают при исследовании хорошо впитывающих воду коллекторов. Примерами таких измерений являются лабораторное нагнетание воды, определение зависимости электрического сопротивления и коэффициента водонасыщенности, изме- 
рение капилдярного давления для определения насыщенности пласта адсорбированной водой. Исследование влияния свойств сырой нефти на её смачиваемость привело к выводу о том, что большинство пластов имеют условия смачиваемости, отличные от ранее признаваемых. Этот вывод способствовал возрождению интереса к исследованиям, связанным с измерением пластовой смачиваемости и определением её влияния на добычу нефти, особенно при использовании технологии нагнетания воды.

Изучение вдияния смачиваемости на добычу нефти осуществдяется методами, которые вкдючают в себя исследование образцов керна и называются расширенным анализом смачиваемости керна. Лабораторные эксперименты показали, что смачиваемость может охватывать широкий диапазон состояний, которые варьируются от чисто гидрофидьного до чисто гидрофобного. В пределах этого диапазона существуют сложные состояния смешанной насыщенности теми или иными флюидами.

Микроструктурная смачиваемость определяется комплексом граничных взаимодействий, действующих в поровом пространстве осадочных пород. Микроструктурная смачиваемость возникает, когда гидрофильные и гидрофобные участки смачивания приурочены к отдельным порам и капилдярам, что приводит к неоднородности смачивания на уровне отдельных пор (микроуровень). Распределение гидрофобных и гидрофильных участков, их число и чередование зависят от природы породообразующих минералов, структуры порового пространства, физико-химических свойств насыщающих жидкостей и содержания в нем погребенной (реликтовой) воды.

Микроструктурная смачиваемость приводит к необычным явлениям при двухфазной фильтрации и требует специального учета для обоснования технологий извлечения углеводородов из пластов. Выявлено, что именно микроструктурная смачиваемость вдияет на фазовую и относительную фазовую проницаемости, капиллярное давление, неподвижную водо- и нефтенасыщенность и в конечном итоге обуславливает углеводородоотдачу пласта

Основными процессами, вдияющими на образование микроструктурной смачиваемости порового пространства пород-колдекторов, являются адсорбционно-хроматографический процесс - процесс, который приводит к обособлению и концентрации зон индивидуадьных компонентов исходных смесей углеводородов и воды на границе раздела фаз: порода - углеводороды, порода - вода и изменение термобарических условий.

В такой многофазной, многокомпонентной системе, какой является коляектор углеводородного сырья, существует постоянная конкуренция в адсорбционном процессе между водой и углеводородами. Преимущество имеет тот компонент, который имеет большую энергию адсорб- ции по отношению к породе [1-6].

Карачаганакское месторождение представдено газовой, газоконденсатной и нефтяной зонами, поэтому является удобным объектом для изучения изменения микроструктурной смачиваемости при переходе из одной зоны в другую.

В выборку, на которой проводидись исследования, вошли образцы керна Карачаганакского месторождения, отобранные из интервала глубин 3762-5644 м., всего 227 образцов из газонасыщенной, газоконденсатной, нефтяной и водонасыщенной зон месторождения.

\section{Экспериментальная часть}

Микроструктурная смачиваемость характеризовалась коэффициентом гидрофобизации, $\theta_{н}$ определяемым на основании изучения закономерностей пленочного течения воды по гидрофобной и гидрофидьной поверхности. Им определяется доля площади поверхности пор, занятая углеводородами [7].

Для определения коэффициента гидрофобизации образцы керна насыщадись под вакуумом дистиляированной водой, затем сушились в климатической камере при температуре $25^{\circ} \mathrm{C}$ и влажности воздуха 33\%. Далее образцы вакуумировались в течение 6 часов при остаточном давлении $1.33^{*} 10^{-6}$ МПа. Потеря свободных углеводородов во время поднятия керна на поверхность, а также вакуумирование образцов керна в течение 6 часов при давлении 1.33*10-6 МПа, позволяет утверждать то, что в ходе эксперимента в образцах керна остается тодько адсорбированные углеводороды, то есть удерживаемые на поверхности поровых каналов адсорбционными силами.

Первая кривая сушки - зависимость влагосодержания образца от времени - была получена для образцов керна с естественной гидрофобизацией. Вторая кривая сушки была получена после экстракции образцов растворителями (рис. 1). Образцы экстрагировались в аппарате Сокслета хлороформом, затем - спиртом до прекращения светимости растворителей в ультрафиолетовом свете. Остатки спирта удалялись водяным паром. После этого рассчитывались коэффициенты гидрофобизации по формуле [7]:

$\theta_{н}=\left(W_{2}-W_{1}\right) / W_{2}$, где

$W_{1}$ - кодичество воды, испарившейся до момента изменения скорости испарения при наличии гидрофобизации;

$W_{2}$ - количество воды, испарившейся до момента изменения скорости испарения после устранения гидрофобизации экстракцией.

Полученный углеводородный экстракт после испарения хлороформа, изучался методом инфракрасной (ИК) спектроскопии, позволяющим определить наличие в смеси групп соединений, имеющих фиксированное химическое строение. ИК-спектр фиксирует наличие определенных полос поглощения или пропускания. Использовался двухлучевой спектрофотометр Specord 75 IR, источник излучения - керамиче- 


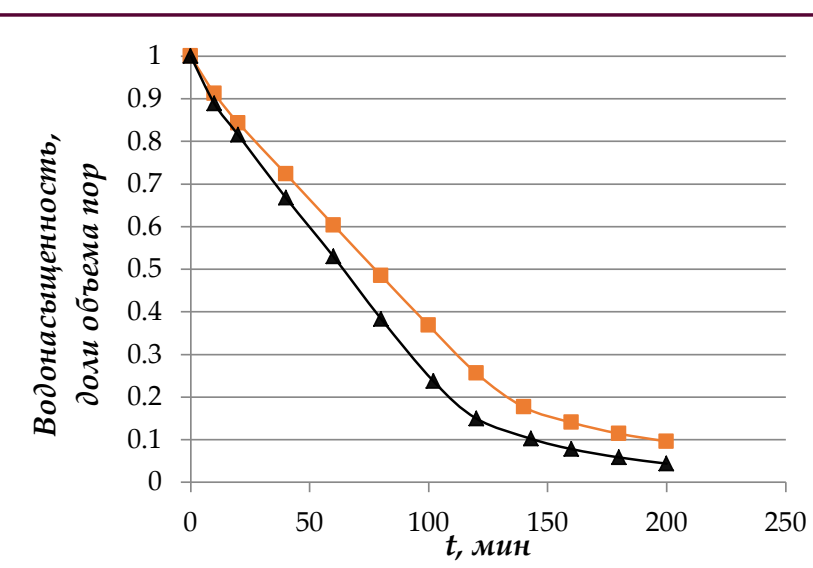

Рис.1. Испарение воды из гидрофобизованного образца (верхняя кривая); из гидрофидьного образца (нижняя кривая)

ский стержень $(d=4.0$ мм $)$ с платино - родиевой спиралью накала $\left(\mathrm{t}^{\circ}=1200{ }^{\circ} \mathrm{C}\right)$. Процентные коэффициенты пропускания проб экстракта определялись 2-х лучевым способом по принципу оптического дифференцирования.

На рисунках 2 и 3 показаны примеры ИК-спектров углеводородов, выделенных из образцов керна экстракцией (адсорбированных углеводородов).

По ИК-спектрам были рассчитаны спектральные коэффициенты, характеризующие наличие в составе адсорбированной нефти: адифатических $(\mathrm{A} \Lambda)$, ароматических (Ар), разветвленных (Р), окисленных (Ок), серосодержащих (С) структур. Эти коэффициенты характеризуют структуры углеводородов наиболее подверженные адсорбционному процессу.

Спектрадьные коэффициенты определялись по количественному соотношению характеристических полос поглощения: полоса 1600 см$^{-1}$ - присутствие ароматических структур; $720 \mathrm{~cm}^{-1}, 1380 \mathrm{~cm}^{-1}$, 1460 см$^{-1}$ - содержание метильных и метиленовых групп в парафиновых цепях; 1710 cм$^{-1}$ - присутствие окисленных структур; 1030 см$^{-1}$ - присутствие осерненных структур. По соотношению оптических плотностей в максимуме данных полос поглощения получены безразмерные спектральные коэффициенты: $\mathrm{Ap}=\mathrm{D}_{1600} / \mathrm{D}_{720} ; \mathrm{A} \lambda=\mathrm{D}_{720+1380} / \mathrm{D}_{1600} ; \mathrm{P}=\mathrm{D}_{720} / \mathrm{D}_{1460}$; $\mathrm{OK}=\mathrm{D}_{1710} / \mathrm{D}_{1460} ; \mathrm{C}=\mathrm{D}_{1030} / \mathrm{D}_{1460}$ [2].

\section{Резудьтаты эксперимента}

Коэффициент гидрофобизации образцов, отнесенных к газонасыщенной зоне, имел одинаковое значение с коэффициентом гидрофобизации из газоконденсатной зоны, то есть, пластовая смесь в этих зонах находится в двух гомогенных фазах - жидкой и газообразной.

В дальнейшем данные, полученные для газонасыщенной зоны быди объединены с данными, полученными для газоконденсатной зоны (табл. 1) как образцы, принадлежащие газоконденсатной зоне.

По полученным данным, коэффициент гидрофобизации изменяется от 0 (в зоне водонефтяного контакта) до 0.512 (в нефтяной зоне) (рис.4)

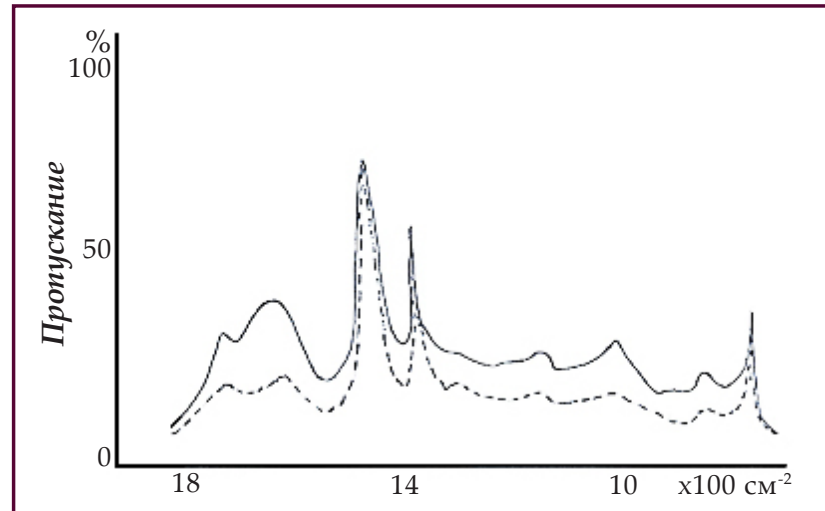

Рис.2. ИК-спектры адсорбированных углеводородов: - газовая зона, --- нефтяная зона

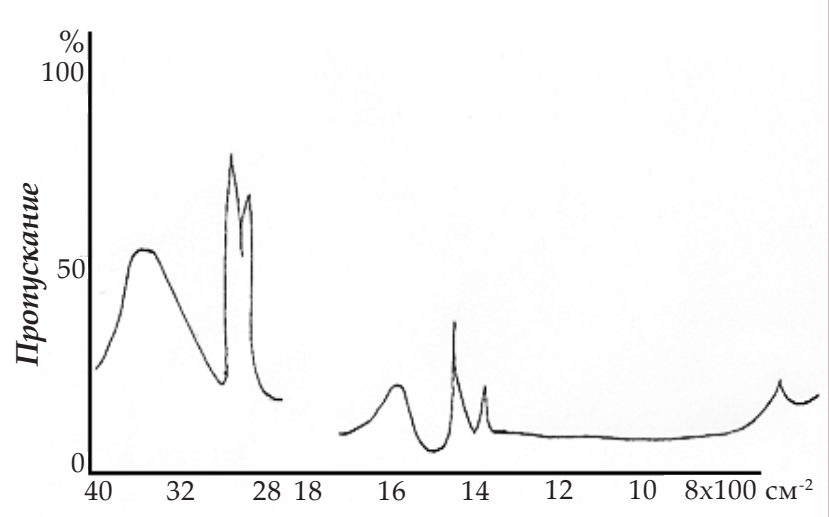

Рис.3. ИК-спектр адсорбированных угдеводородов из зоны водонефтяного контакта

В таблице 1 приведены средние значения параметров, характеризующих коллекторские свойства, состав пород и коэффициент гидрофобизации для газоконденсатной и нефтяной зон. Из таблицы следует, что раздичие в колдекторских свойствах и в составе пород этих зон минимальные, а коэффициент гидрофобизации в 1.8 раза выше в нефтяной зоне.

Из этого следует вывод, что коэффициент гидрофобизации зависит от состава адсорбированных углеводородов. Это подтверждают спектральные исследования, которые показали раздичия в составе адсорбированных углеводородов, вдияющие на микроструктурную смачиваемость. Так характеристические полосы в ИК-спектрах показали наличие в составе адсорбированных углеводородов из газоконденсатой и нефтяной зон (рис. 2) окисленных, серосодержащих, аро-

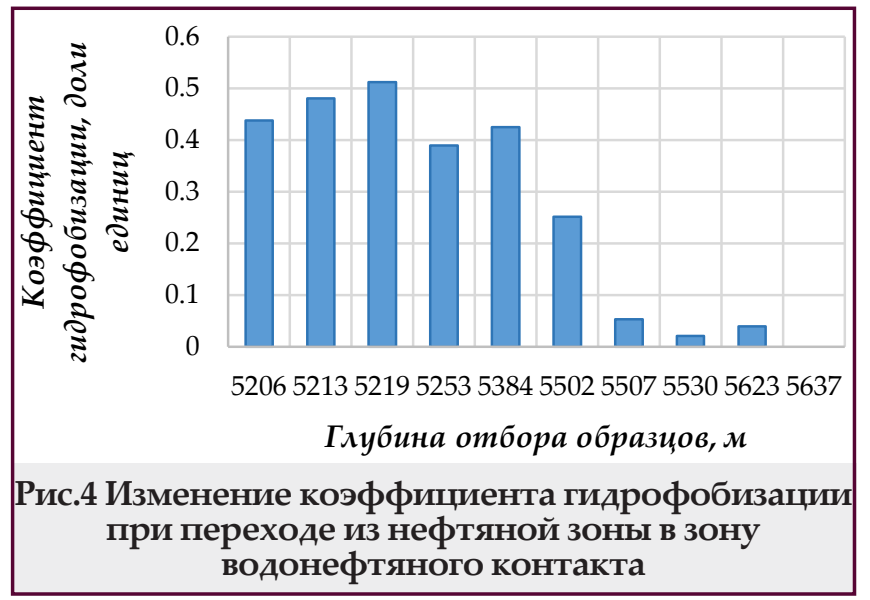


Таблица 1

Средние значения колдекторских свойств, коэффициента гидрофобизации, состава пород в выделенных зонах

\begin{tabular}{|c|c|c|c|c|c|c|c|c|}
\hline Зоны & $\boldsymbol{K}_{\text {оп }}$ & $\boldsymbol{K}_{\text {эфф }}$ & $\boldsymbol{K}_{n p}$ & $\boldsymbol{\theta}_{\boldsymbol{u}}$ & $\mathrm{CaCO}_{3}$ & $\left.\mathrm{CaMg}_{\left(\mathbf{C O}_{3}\right.}\right)_{2}$ & $\mathbf{C a S O}_{4}$ & но \\
\hline Газоконденсатная & 0.123 & 0.108 & 28.6 & 0.140 & 26.4 & 70.2 & 3.2 & 0.2 \\
\hline Нефтяная & 0.113 & 0.099 & 33.4 & 0.250 & 38.5 & 55.0 & 4.4 & 2.1 \\
\hline
\end{tabular}

$K_{\text {on }}$ - коэффициент открытой пористости, доли единиц.

$K_{\text {эфф }}$ - коэффициент эффективной пористости, доли единиц.

$K_{n p}$ - коэффициент газопроницаемости $1^{*} 10^{-15} \mathrm{M}^{2}$.

$\mathrm{CaCO}_{3}$ - содержание известняка, \%

$\mathrm{CaMg}\left(\mathrm{CO}_{3}\right)_{2}$ - содержание доломита, \%

$\mathrm{CaSO}_{4}$ - содержание ангидрита, \%

но - содержание нерастворимого остатка, \%

$\theta_{н}-$ коэффициент гидрофобизации, доля площади поверхности пор, занятая угдеводородами.

матических структур, метильных и метиленовых групп в парафиновых цепях. В тех образцах, где содержание этих структур бодьше, коэффициент гидрофобизации выше. В таблице 2 приведены значения спектральных коэффициентов, характеризующих наличие выше указанных структур в образцах из газоконденсатной и нефтяной зон.

Нефтяная зона характеризуется большим содержанием в углеводородах ароматических, алифатических, окисленных и серосодержащих структур и меньшим содержанием разветвленных структур по сравнению с газоконденсатной зоной. Поэтому, коэффициент гидрофобизации нефтяной зоны выше, чем газоконденсатной. На рисунке 3 показан ИК-спектр адсорбированных углеводородов, выделенных из образцов керна, находящихся непосредственно в зоне водонефтяного контакта. В спектре нет характеристических полос, отвечающих за образование гидрофобных участков поверхности. Но есть полосы, показывающие надичие воды, метильных и метиленовых групп в парафиновых цепях. Коэффициент гидрофобизации здесь равен 0. Поверхность образцов гидрофильна, а углеводороды связаны непосредственно с молекулами адсорбированной воды водородными связями.

\begin{tabular}{|c|c|c|c|c|c|}
\hline \multicolumn{8}{|c|}{ Спектральные коэффициенты, рассчитанные для газоконденсатной и нефтяной зон } \\
\hline Зона & $\mathbf{A p}$ & $\mathbf{A л}$ & $\mathbf{P}$ & Ок & $\mathbf{C}$ \\
\hline Газоконденсатная & 0.412 & 1.12 & 0.485 & 0.232 & 0.182 \\
\hline Нефтяная & 1.22 & 2.38 & 0.36 & 0.359 & 0.339 \\
\hline
\end{tabular}

\section{Выводы}

-Исследованная выборка карбонат-ных пород по составу неоднородна.

-По подученным данным коэффициент гидрофобизации изменяется от 0 (в зоне водонефтяного контакта) до 0.512 (в нефтяной зоне)

-Коэффициент гидрофобизации, характеризующий микроструктурную смачиваемость, составдяет в среднем: для газовой и газоконденсатной зон 0.14, а для нефтяной зоны 0.25. То есть, в первом случае порода гидрофильна на $86 \%$, а во втором на $75 \%$.

-Микроструктурная смачиваемость изученных образцов зависит от состава адсорбированныхуглеводородов. Чем больше в составе адсорбированных углеводородов структур, способных к адсорбции, тем выше коэффициент гидрофобизации.

- Микроструктурная смачиваемость образцов из нефтяной зоны выше, чем у образцов из газоконденсатной зоны. Микроструктурная смачиваемость может служить характеристикой состава углеводородного сырья в пластах.

-Исследования микроструктурной смачиваемости показывают, что требуется специальный учет смачиваемости для обоснования технологий извлечения углеводородов из пластов. 


\section{Aumepamypa}

1. Cuiec, L. E. (1990). Evaluation of reservoir wettability and its effect on oil recovery /In: Interfacial phenomena in oil recovery, N.R. Morrow (ed.). New York: Marcell Dekker.

2. Михайлов, Н. Н., Сечина, А. С., Михайлов, А. Н. (2017). Микроструктурная смачиваемость карбонатных газоконденсатонасыщенных коллекторов. Геология, геофизика и разработка нефтяных и газовых месторождений, 8, 45-51.

3. Михайлов, Н. Н., Ермилов, О. М., Сечина, А. С. (2020). Вдияние компонентного состава адсорбированной нефти на микроструктурную смачиваемость карбонатных колдекторов. Доклады Академии Наук. Науки о Земле, 496(2), 1-6.

4. Кузьмин, В. А., Михайлов, Н. Н., Скибицкая, Н. А. и др. (2015). Результаты электронномикроскопических исследований влияния микроструктурных факторов порового пространства коллектора на характер насыщения нефтью. Геология нефти и газа, 3, 34-44.

5. Михайлов, Н. Н., Семенова, Н. А., Сечина, А. С. (2011). Влияние микроструктурной смачиваемости на петрофизические характеристики пород-колиекторов. Каротажник, 7, 163-172.

6. Anderson, W. G. (1986). Wettability literature survey - Part 1: Rock/oil/drine interacnions and the effects of core handling on wettability. Journal of Petroleum Technology, 38, 1125-1144.

7. Танкаева, А. К., Дмитриевский, А. Н., Сечина, А. С., Приваленко, Н. В. (1983). Способ определения степени гидрофобизации поверхности пор. Авторское свидетельство СССР 1022005.

\section{References}

1. Cuiec, L. E. (1990). Evaluation of reservoir wettability and its effect on oil recovery /In: Interfacial phenomena in oil recovery, N.R. Morrow (ed.). New York: Marcell Dekker.

2. Mikhailov, N. N., Sechina, L. S., Mikhailov, A. N. (2017). Microstructural wettability of carbonate gas-condensate saturated collectors. Geology, Geophysics and Development of Oil and Gas Fields, 8, 45-51.

3. Mikhailov, N. N., Ermilov, O. M., Sechina, L. S., Menshikova, D. S. (2020). Influence of the component composition of adsorbed oil on the microstructural wettability of hydrocarbon reservoirs. Doklady Earth Sciences, 496(2), 1-6.

4. Kuzmin, V. A., Mikhaylov, N. N., Skibitskaya, N. A., et al. (2015). Results of the electronmicroscopic research on the impact of microstructural factors of reservoir space on the oil saturation pattern. Geology of Oil and Gas, 3, 34-44.

5. Mikhailov, N. N., Semenova, N. A., Sechina, L. S. (2011). The influence of microstructure wetting on the petrophysical characteristics of the reservoir rocks. Karotazhnik, 7, 163-172.

6. Anderson, W. G. (1986). Wettability literature survey - Part 1: Rock/oil/drine interacnions and the effects of core handling on wettability. Journal of Petroleum Technology, 38, 1125-1144.

7. Tankaeva, L. K., Dmitrievskij, A. N., Sechina, L. S., Privalenko, N. V. (1983). Sposob opredeleniya stepeni gidrofobizacii poverhnosti por. Avtorskoe svidetel'stvo SSSR 1022005. 


\title{
Микроструктурная смачиваемость нефтегазоконденсатных зон Карачаганакского месторождения
}

\author{
H.Н. Михайлов ${ }^{1,2,}$ А.С. Сечина ${ }^{* 2}$ \\ ${ }^{1}$ Российский государственный университет \\ нефти и газа (НИУ) им. И.М. Губкина, Москва, Россия; \\ ${ }^{2}$ Институт проблем нефти и газа \\ Российской академии наук, Москва, Россия
}

\section{Реферат}

Карачаганакское месторождение представленное, газоконденсатной и нефтяной зонами, представительный объект для изучения изменения микроструктурной смачиваемости при переходе из одной зоны в другую. Микроструктурная смачиваемость характеризоваиась коэффициентом гидрофобизации $\Theta_{\text {н }}$ который определяет долю площади поверх-

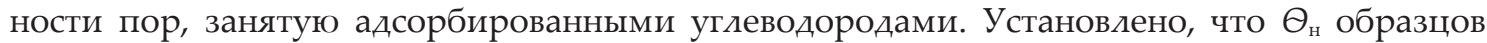
газовой и газоконденсатной зон одинаков (в среднем 0.140), нефтяной зоны - в среднем 0.250. Анализ ИК-спектров экстрагированных углеводородов показал, что микроструктурная смачиваемость нефтяной зоны содержит больше ароматических, алифатических, окисленных и серосодержащих структур и меньше разветвленных структур, чем в газоконденсатной зоне. Микроструктурная смачиваемость карбонатных коллекторов зависит от углеводородного состава адсорбированной нефти.

Ключевые слова: микроструктурная смачиваемость; коэффициент гидрофобизации; углеводороды; структурные коэффициенты.

\section{Qaraçaqanak yatağının neft-qaz-kondensat zonalarının mikrostruktur islanma qabiliyyəti}

\author{
N.N. Mihaylov ${ }^{1,2}$, L.S. Seçina ${ }^{* 2}$ \\ ${ }^{1}$ Rusiya Elmlər Akademiyasinin \\ Neft və Qaz Problemləri Institutu, Moskva, Rusiya; \\ ${ }^{2}$ «Atombiotech» ETF MMC, Moskva, Rusiya
}

\begin{abstract}
Xülasə
Bir zonadan digərinə keçid zamanı mikrostruktur islanma qabiliyyətinin dəyişməsini öyrənmək məqsədilə nümayiş obyekti kimi qazkondensat və neft zonaları ilə təmsil olunan Qaraçaqanak yatağı götürülür. Mikrostruktur islanma qabiliyyəti adsorbsiya olunmuş karbohidrogenlər ilə tutulan məsamələr səthinin sahəsini müəyyən edən hidrofoblaşma əmsalı $\Theta_{н}$ ilə xarakterizə olunur. Müəyyən edilmişdir ki, qaz və qaz-kondensat zonalarından nümunələr üçün $\Theta_{н}$ eynidir (orta hesabla 0.140), neft zonasının nümunələri üçün orta hesabla 0.250 təşkil edir. Ekstraksiya olunmuş karbohidrogenlərin İQ-spektrlərin təhlili göstərir ki, neft zonasının mikrostruktur islanma qabiliyyəti qazkondensat zonasına nisbətən daha çox aromatik, alifatik, oksidləşmiş və kükürdlü strukturlardan və daha az şaxələnmiş strukturlardan ibarətdir. Karbonat kollektorlarının mikrostruktur islanma qabiliyyəti adsorbasiya edilmiş neftin karbohidrogen tərkibindən asılıdır
\end{abstract}

Açar sözlər: : mikrostruktur islanma qabiliyyəti; hidrofoblaşma əmsall; karbohidrogenlər; struktur əmsalları. 